\title{
Bubble Curtains: Herbivore Exclusion Devices for Ecology and Restoration of Marine Ecosystems?
}

\author{
Scott Bennett ${ }^{1,2 *}$, Thomas Wernberg ${ }^{2}$ and Thibaut de Bettignies ${ }^{2,3}$ \\ ${ }^{1}$ Department of Global Change Research, Institut Mediterrani d'Estudis Avançats, Universitat de les Illes Balears-Consejo \\ Superior de Investigaciones Cientificas, Esporles, Spain, ${ }^{2}$ School of Biological Sciences, UWA Oceans Institute, Crawley, \\ WA, Australia, ${ }^{3}$ UMS 2006 Patrimoine Naturel, Muséum National d'Histoire Naturelle, Paris, France
}

Herbivorous fishes play a critical role in maintaining or disrupting the ecological resilience of many kelp forests, coral reefs and seagrass ecosystems, worldwide. The increasing rate and scale of benthic habitat loss under global change has magnified the importance of herbivores and highlights the need to study marine herbivory at ecologically relevant scales. Currently, underwater herbivore exclusions (or inclusions) have been restricted to small scale experimental plots, in large part due to the challenges of designing structures that can withstand the physical forces of waves and currents, without drastically altering the physical environment inside the exclusion area. We tested the ability of bubble curtains to deter herbivorous fishes from feeding on seaweeds as an alternative to the use of rigid exclusion cages. Kelps (Ecklonia radiata) were transplanted onto reefs with high browsing herbivore pressure into either unprotected plots, exclusion cages or plots protected by bubble curtains of $0.785 \mathrm{~m}^{2}$ and $3.14 \mathrm{~m}^{2}$. Remote underwater video was used to compare the behavioral response of fishes to kelps protected and unprotected by bubble curtains. Kelp biomass loss was significantly lower inside the bubble curtains compared to unprotected kelps and did not differ from kelp loss rates in traditional exclusion cages. Consistent with this finding, no herbivorous fishes were observed entering into the bubble curtain at any point during the experiment. In contrast, fish bite rates on unprotected kelps were 1,621 \pm 702 bites $^{-1}$ (mean \pm SE). Our study provides initial evidence that bubble curtains can exclude herbivorous fishes, paving the way for future studies to examine their application at larger spatial and temporal scales, beyond what has been previously feasible using traditional exclusion cages.

\section{Keywords: fish herbivory, rocky reefs, kelp, ecological resilience, trophic interactions, community ecology}

\section{INTRODUCTION}

Consumers have a profound effect on the structure and function of vegetated communities across a diverse range of ecosystems (Bellwood et al., 2004; Wolf et al., 2007; Poore et al., 2012; Bertness et al., 2014; Bennett et al., 2015). In marine systems, herbivores are estimated to consume $68 \%$ of benthic primary production on average globally (Poore et al., 2012). Moreover, abrupt changes in herbivore abundances and over-grazing have contributed to catastrophic regime shifts from vegetated to denuded states in temperate systems (Ling et al., 2009; Filbee-Dexter and Scheibling, 2014; Bennett et al., 2015; Vergés et al., 2016), while a decline of herbivores (e.g., scrapers, 
excavators and browsers; sensu Bellwood and Choat, 1990) on coral reefs has been closely associated with undesirable regime shifts from coral to seaweed dominated states (Bellwood et al., 2004; Mumby et al., 2006; Hughes et al., 2007). In addition to the direct effects of herbivores, many vegetated marine ecosystems such as seagrass meadows and kelp forests are in decline as a result of anthropogenic disturbances from eutrophication, climatic warming and extreme events, sediment-loading, salinity changes and invasive species (Orth et al., 2006; Waycott et al., 2009; Wernberg et al., 2013, 2016; Bennett et al., 2016; Krumhansl et al., 2016). This has prompted efforts to actively revegetate coastal marine systems to curb losses and restore habitats where the initial cause of the loss has been reduced (Bastyan and Cambridge, 2008; Statton et al., 2013; Campbell et al., 2014). A critical challenge for many such restoration efforts is to control the impact of herbivores, which can overgraze the patches being restored, particularly in the early stages before the vegetation has had a chance to properly establish (Statton et al., 2015). Grazing intensity by roving herbivores decreases with increasing patch size, both as a result of diffusion of grazing pressure on individual plants (i.e., more biomass to be shared among the herbivore assemblage), but also as a behavioral response of browsing fishes which preferentially target small patches to feed on (Hoey and Bellwood, 2011). Therefore, the larger the area that can be restored before being exposed to herbivores, the greater the chance of success (also see Discussion about sustainable patch size for exclusion areas).

Methods for eliminating herbivores in marine studies include the physical removal of the organism, chemical barriers and exclusion cages (Poore et al., 2012). Physical removal (e.g., McClanahan et al., 1996) and chemical barriers (e.g., Menge et al., 1999) can be very effective for benthic invertebrates such as gastropods and sea urchins, which have limited mobility and relatively small home ranges. Roving herbivorous fishes on the other hand can have home ranges of several kilometers and move freely throughout the water column (Pagès et al., 2013; Welsh and Bellwood, 2014), making exclusion cages the only option to prevent grazing. In addition to their high mobility, herbivorous fish assemblages can be large (i.e., $\sim 10-30 \mathrm{~kg} 100$ $\mathrm{m}^{-2}$ ), (Wismer et al., 2009; Bennett et al., 2015) and can represent over $85 \%$ of the biomass of the entire fish assemblage (Bennett et al., 2015). The size and mobility of herbivorous fishes mean that establishing sufficient plant biomass to revegetate an area to the point where production exceeds consumption capacity of the herbivore community can be challenging. On a fringing coral reef, for example, it has been conservatively estimated that an exclusion area of $75-115 \mathrm{~m}^{2}$ would be required for tropical Sargassum production to outpace consumption by the local browsing herbivore assemblage (Hoey and Bellwood, 2011).

Excluding fish herbivores is difficult due to the logistics of designing a structure that can withstand the physical forces of waves and currents, while at the same time not drastically altering the physical environment inside the exclusion area. These challenges have limited the application of underwater exclusion cages to relatively small scale and short term experiments (but see Hughes et al., 2007). To date, the mean exclusion cage size for subtidal experiments has been $1.05 \pm 0.27 \mathrm{~m}^{2}$ (mean $\pm \mathrm{SE}$ ) with a median exclusion area of $0.06 \mathrm{~m}^{2}(N=183$, Figure $\mathrm{S} 1)$ (Poore et al., 2012); suitable for the exclusion of fish herbivores from a single plant or assay. While there can be multiple reasons for using small exclusion areas, this trend is partly due to the logistical and practical limitations of constructing and maintaining large underwater structures with minimal artifacts. The largest subtidal fish exclusion experiment, that we are aware of, constructed replicate $25 \mathrm{~m}^{2}$ exclusion cages on a shallow $(\sim 3 \mathrm{~m})$ fringing coral reef flat in a sheltered bay, protected from trade winds and ocean swell (Hughes et al., 2007). In this seminal experiment, the exclusion cages breached the surface of the water, eliminating the need for a roof and thereby minimizing shading artifacts. Moreover, the proximity to a research station enabled the cages to be frequently cleaned. However, for most places where the implementation of large underwater exclusion cages is desirable, such controlled field settings may not exist. Instead, wave exposure, depth, limited accessibility and public safety concerns can impede the implementation and maintenance of comparable, let alone larger underwater structures.

A potential alternative to cages that would overcome some of the logistical challenges of rigid structures are bubble curtains. Bubbles or bubble curtains have been observed to modify animal behavior in both natural and human modified aquatic systems. Among marine mammals, humpback whales (Megaptera novaeangliae) and several species of dolphin are known to create cylindrical "bubble nets" to herd their prey for feeding (Sharpe and Dill, 1997; Neumann and Orams, 2003; Wiley et al., 2011). Bubble curtains have also been applied for fish herding in fishing and aquaculture, as a means of guiding fish in set-net fishing operations and retaining fish in enclosures (Stewart, 1982; Arimoto et al., 1993). Perhaps the most common application of bubble curtains, however, has been as a barrier to guide and deter the movement of aquatic species (Sager et al., 1987; Dawson et al., 2006; Zielinski et al., 2014; Hart and Collin, 2015). As deterrents, bubbles have been trialed and applied to prevent fish entering hydroelectric power stations (Linnansaari et al., 2015), restrict the movement of invasive species (Dawson et al., 2006; Zielinski et al., 2014) and as shark deterrents (Hart and Collin, 2015). However, despite the success of bubbles in restricting fish movements in other systems, currently their potential application has never been tested on reef fishes, or as a method to prevent herbivores from feeding on marine vegetation.

If bubble curtains are able to restrict the movements of mobile marine herbivores from entering into an area of reef, the potential benefits and applications could be significant for both marine ecological studies and restoration programs (Table 1). Unlike rigid cages, the "walls" of bubble curtains do not experience marine fouling, eliminating the need for cleaning and ensuring stable light conditions within the enclosure. Moreover, given the bubbles rise to the surface, they reduce the need for a roof, further minimizing the impact of the enclosure on the light environment. Another significant advantage of bubble curtains over rigid cages is the low profile and drag of the physical structure reducing its risk of being dislodged by waves and currents. Air hoses used to generate bubble curtains are flexible and can therefore fit to the contour of a reef and theoretically be deployed in more exposed areas, where the drag forces on a rigid cage can 
TABLE 1 | Advantages, disadvantages, uncertainties and current applications of exclusion cages and bubble curtains in aquatic systems.

\begin{tabular}{|c|c|c|c|}
\hline Method & Advantages & Disadvantages and uncertainties & Existing applications in marine systems \\
\hline $\begin{array}{l}\text { Exclusion } \\
\text { cages }\end{array}$ & $\begin{array}{l}\text { - Rigid barrier-herbivores cannot pass } \\
\text { - Stand-alone } \\
\text { - Easily deployed for short term experiments }\end{array}$ & $\begin{array}{l}\text { - Rapid fouling resulting in deteriorating light } \\
\text { levels, high maintenance, reduced water flow } \\
\text { - High drag: require sheltered environments to } \\
\text { avoid dislodgement } \\
\text { - Small size: restricted to small experimental } \\
\text { patches } \\
\text { - Difficult to setup in complex habitat }\end{array}$ & $\begin{array}{l}\text { - Ecological experiments: herbivore exclusion } \\
((\text { Hughes et al., 2007; Burkepile and Hay, 2008; } \\
\text { Pagès et al., 2012)) } \\
\text { - Aquaculture: fish pens for holding, rearing and } \\
\text { transporting stock } \\
\text { - Protection from predators }\end{array}$ \\
\hline $\begin{array}{l}\text { Bubble } \\
\text { curtains }\end{array}$ & $\begin{array}{l}\text { - No fouling } \\
\text { - No roof required as bubbles go to the surface } \\
\text { - Volume of exclusion area } \\
\text { - Minimal and consistent light modification } \\
\text { over time } \\
\text { - Low maintenance } \\
\text { - Low profile - can be deployed in exposed } \\
\text { habitats }\end{array}$ & $\begin{array}{l}\text { - } \text { Reliant on constant power generation and air } \\
\text { - } \text { Rupply for long term study } \\
\text { large scale or deep enclosures } \\
\text { - Long term habituation by herbivores } \\
\text { (resulting in breaches), untested } \\
\text { - Long term durability of bubble curtain hose } \\
\text { under constant immersion untested } \\
\text { - Effects on water flow untested } \\
\text { - Modification of seaweed propagule or larval } \\
\text { settlement could pass through bubbles, } \\
\text { - } \text { untested }\end{array}$ & $\begin{array}{l}\text { - Nature: prey herding by marine mammals (Sharpe } \\
\text { and Dill, 1997; Neumann and Orams, 2003; Wiley } \\
\text { et al., 2011) } \\
\text { - Aquaculture: fish herding in aquaculture (Arimoto } \\
\text { et al., 1993) } \\
\text { - Fish deterrence in hydro-electric power stations } \\
\text { (Patrick et al., 1985; Sager et al., 1987) } \\
\text { - Prevent the spread of invasive fishes in freshwater } \\
\text { systems (Dawson et al., 2006; Zielinski et al., 2014) } \\
\text { - Shark protection (Hart and Collin, 2015) } \\
\text { - Reduce noise pollution (Würsig et al., 2000; } \\
\text { Lucke et al., 2011) }\end{array}$ \\
\hline
\end{tabular}

become a limiting factor (but see Sumi and Scheibling, 2005). Finally, by eliminating the need for a rigid three-dimensional structure, bubble curtains also reduce the physical hazard to users of the marine environment where they are deployed. Collectively these features of bubble curtains could reduce some of the limitations which prevent the use of large rigid cages in ecological experiments and restoration programs underwater.

Currently it remains unclear whether bubble curtains could modify the behavior of herbivorous fishes and prevent them from overgrazing marine vegetation. In this study, we aimed to test the efficacy of simple bubble curtains as an exclusion device for herbivorous fishes. Specifically, we ask whether changes in transplanted seaweed biomass and fish feeding rates differ among unprotected transplants, caged transplants or transplants protected by bubble curtains. In addition, we compare bubble curtains with a benthic exclusion area of 0.785 and $3.14 \mathrm{~m}^{2}$ to examine the effect of curtain size on herbivore exclusion. Our study provides an initial and novel examination of the potential for bubble curtains to exclude marine herbivores.

\section{METHODS}

\section{Study Site and Experimental Design}

The study was conducted in September 2014 on shallow (2$5 \mathrm{~m})$ reef habitats in Port Gregory, Western Australia (28.2 $2^{\circ} \mathrm{S}$, $114.2^{\circ} \mathrm{E}$ ). Port Gregory was chosen for this study because it has some of the highest browsing herbivore biomass and feeding rates reported from either temperate or tropical reef systems (Bennett et al., 2015). A total of five feeding trials were conducted over 3 days, resulting in $n=10$ replicates per treatment. Replicate trials lasted $2 \mathrm{~h}$ and were conducted during daylight hours between 0800 and 1600. In each replicate trial, kelps were transplanted into unprotected plots $(n=2)$, cages $(n=2)$, and bubble curtains $(n=1$ for each bubble curtain with exclusion areas of 0.785 and $3.14 \mathrm{~m}^{2}$ ). Each trial was conducted in a different part of the reef. All trials were conducted on turf dominated $(<1 \mathrm{~cm}$ algal height) rocky reefs between 2 and $5 \mathrm{~m}$ depth. Sea conditions were fare and similar among trial sites throughout the experiment. Unprotected, caged and bubble curtain plots were all separated by at least $5 \mathrm{~m}$ on the reef.

\section{Bubble Curtain Setup and Methodology}

Bubble curtains were produced using a petrol powered air compressor, mounted on the deck of a small research vessel, which remained on anchor throughout the course of the experiment. A $30 \mathrm{~m}$ line of $5 \mathrm{~mm}$ air hose delivered compressed air to a $\mathrm{T}$ section, which split into two $10 \mathrm{~m}$ air lines, connected to the $0.785 \mathrm{~m}^{2}$ and $3.14 \mathrm{~m}^{2}$ arrays, respectively. Bubble arrays were weighted to the bottom using $10 \mathrm{~mm}$ galvanized chain, enabling them to follow the contour of the reef and remain fixed to the bottom. Bubble arrays were attached to the chain using cable ties to form circular enclosures of 1 and $2 \mathrm{~m}$ diameter. Bubble arrays were constructed using "Pope water-weeper" garden soaker hose ( $4 \mathrm{~mm}$ hose diameter). The bubble hose was made from $60 \%$ rubber perforated by thousands of micro pores, enabling a fine mist of bubbles to escape through the wall of the hose. Circular bubble arrays were attached to the air hose via " $\mathrm{T}$ " fittings, enabling the compressed air to be pumped evenly in both directions around the circular array. The line pressure of the hose was maintained between 20 and 30 PSI throughout the experiment creating an even and continuous stream of tiny bubbles, resembling a semi opaque curtain (Figures 1A,B).

\section{Kelp Translocation Method}

Ecklonia radiata (a small kelp) individuals were translocated from Marmion $\left(31.82^{\circ} \mathrm{S}, 115.70^{\circ} \mathrm{E}\right)$ to Port Gregory. Ecklonia radiata was used as it had been observed to be readily consumed by browsing fish herbivores in Port Gregory and was the 


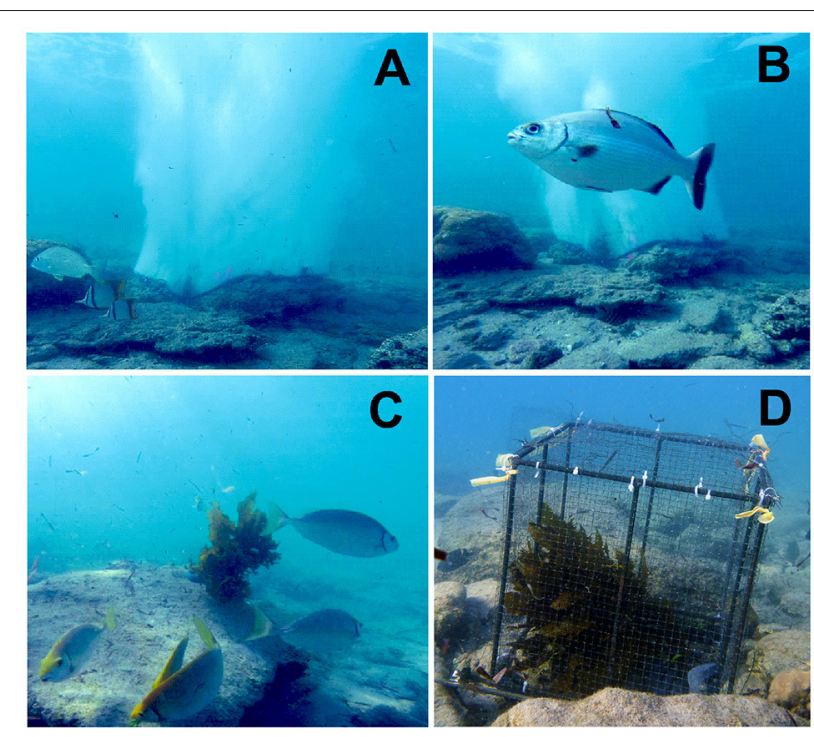

FIGURE 1 | Photos of the different experimental treatments and principal herbivorous fishes. (A) $0.785 \mathrm{~m}^{2}$ bubble curtain with kelp inside (B) Kyphosus sydneyanus in front of bubble curtain, (C) Siganus fuscescens feeding on unprotected kelp, (D) traditional rigid exclusion cage with kelp inside. Photos (A-C) captured from remote video footage. Photo (D) courtesy of TW.

most abundant canopy species at the location prior to its disappearance in 2011 (Bennett et al., 2015; Wernberg et al., 2016). Translocated kelps were collected whole, with the holdfast intact and transported to the laboratory in cool, damp and dark calico bags, where they were individually weighed, measured and tagged. The kelps were then stored in cool damp and dark conditions throughout their transportation and deployed back into the sea within $24 \mathrm{~h}$ of collection (following Bennett et al., 2015). Kelps were randomly allocated among treatments and each trial used fresh kelps. In addition to the two bubble curtain arrays, two unprotected kelps were transplanted to the reef (Figure 1C) and two conventional exclusion cages (Figure 1D) were set up at each site to control for non-macroherbivore related kelp loss. Cages were constructed with $600 \times 600 \times 500 \mathrm{~mm}$ stainless steel frames covered in $10 \times 10 \mathrm{~mm}$ mesh. Replicate kelps from the four treatments were haphazardly arranged on the reef. Each kelp was separated by at least $5 \mathrm{~m}$ from one another. Kelps were weighted onto the reef by $1.5 \mathrm{~kg}$ of lead, attached with cable ties around the holdfast (Bennett et al., 2015). Following the $2 \mathrm{~h}$ feeding trial, translocated kelps were recollected and transported to the laboratory where fresh weight and length were re-measured to assess herbivore impact.

\section{Fish Feeding Rates}

Remote underwater video cameras (GoPro Hero3) were used to assess fish feeding rates on the transplanted kelps and behavioral responses to the bubble curtains. Two replicate $2 \mathrm{~h}$ remote-video recordings were taken during daylight hours between 0800 and 1600. Feeding rates on kelps were analyzed using EventMeasure software (SeaGIS Pty Ltd) by quantifying the bite rates by each fish species over the course of the filming period. The maximum number of individuals of each species within the field view at the same time $(\mathrm{MaxN})$ was also recorded as a conservative measure of relative abundance (Cappo et al., 2003) around the small bubble curtain and unprotected kelps. Deterrence rates were measured to compare the behavioral responses of herbivorous fishes around kelps protected by bubble curtains with unprotected kelps. Deterrence events were recorded when a fish approached either the bubble curtain or unprotected kelp, but then abruptly altered direction by at least $90^{\circ}$ within $1.5 \mathrm{~m}$ of the target, without penetrating the bubble curtain or without reaching the kelp (in unprotected plots). MaxN and deterrence rates around the $3.14 \mathrm{~m}^{2}$ bubble curtain were not included, because the field of view of the camera was not sufficiently large to observe fish behavior either side of the bubble curtain. Fish behavior in response to rigid exclusion cages was not recorded.

\section{Statistical Analyses}

The effect of herbivore exclusion treatments on kelp biomass loss was tested using analysis of variance (ANOVA). A random block design ANOVA was used to examine the effect of bubble treatment ( 0.785 and $3.14 \mathrm{~m}^{2}$ bubble arrays; fixed factor) on kelp loss rates within replicate Trials (random factor, 5 levels). No difference in kelp loss was observed between the two bubble array sizes [ANOVA, $F_{(1,4)}=0.282, p=0.623$ ] and so 0.785 and $3.14 \mathrm{~m}^{2}$ bubble arrays were pooled for subsequent analysis. The proportion of kelp biomass lost after each trial (random factor 5 levels) was compared among herbivore exclusion Treatments (fixed factor, 3 levels). Data were checked for normality and homogeneity of variance through visual inspection of scatter plots and the distribution of residuals. The proportion of kelp loss was square-root arcsine transformed to improve normality and homoscedasticity. The effect of exclusion treatment (fixed factor, 2 levels: $0.785 \mathrm{~m}^{2}$ bubble curtain and unprotected kelp) on herbivore deterrence rates and combined herbivore abundance $(\mathrm{MaxN})$ were similarly tested with a random block design ANOVA, with Trial used as a random explanatory variable. One open plot from each Trial was randomly selected to provide equal sample sizes for the analyses.

\section{RESULTS}

Biomass loss rates of tethered kelps without any form of herbivore exclusion, were $153.8 \pm 48.3 \mathrm{~g} \mathrm{FW} \mathrm{h}^{-1}$ (mean \pm $\mathrm{SE}$ ), representing $32.5 \pm 10.2 \% \mathrm{~h}^{-1}$ of initial kelp biomass (Figure 2A). In contrast, biomass loss rates from kelps within exclusion cages $\left(20.72 \pm 8.62 \mathrm{~g} \mathrm{FW} \mathrm{h}^{-1}\right)$ and bubble curtains $\left(24.1 \pm 7.23 \mathrm{~g} \mathrm{FW} \mathrm{h}^{-1}\right)$ were significantly lower, representing a mean loss rate of $4.5 \pm 1.9$ and $5.2 \pm 0.78 \%$, respectively [ANOVA, $\left.F_{(2,8)}=7.62, p=0.014\right]$. Kelp biomass losses were similar within the bubble curtains and rigid exclusion cages (Figure 2A).

Consistent with the low kelp biomass loss rates, no bites or entries of herbivorous fish into the bubble curtain were observed at any point during the experiment (Figure 2B). In contrast, mass standardized fish bite rates on translocated kelps without herbivore exclusion structures were 1,621 \pm 702 bites $^{-1}$ (mean \pm SE) among all species. Four species were observed feeding on 

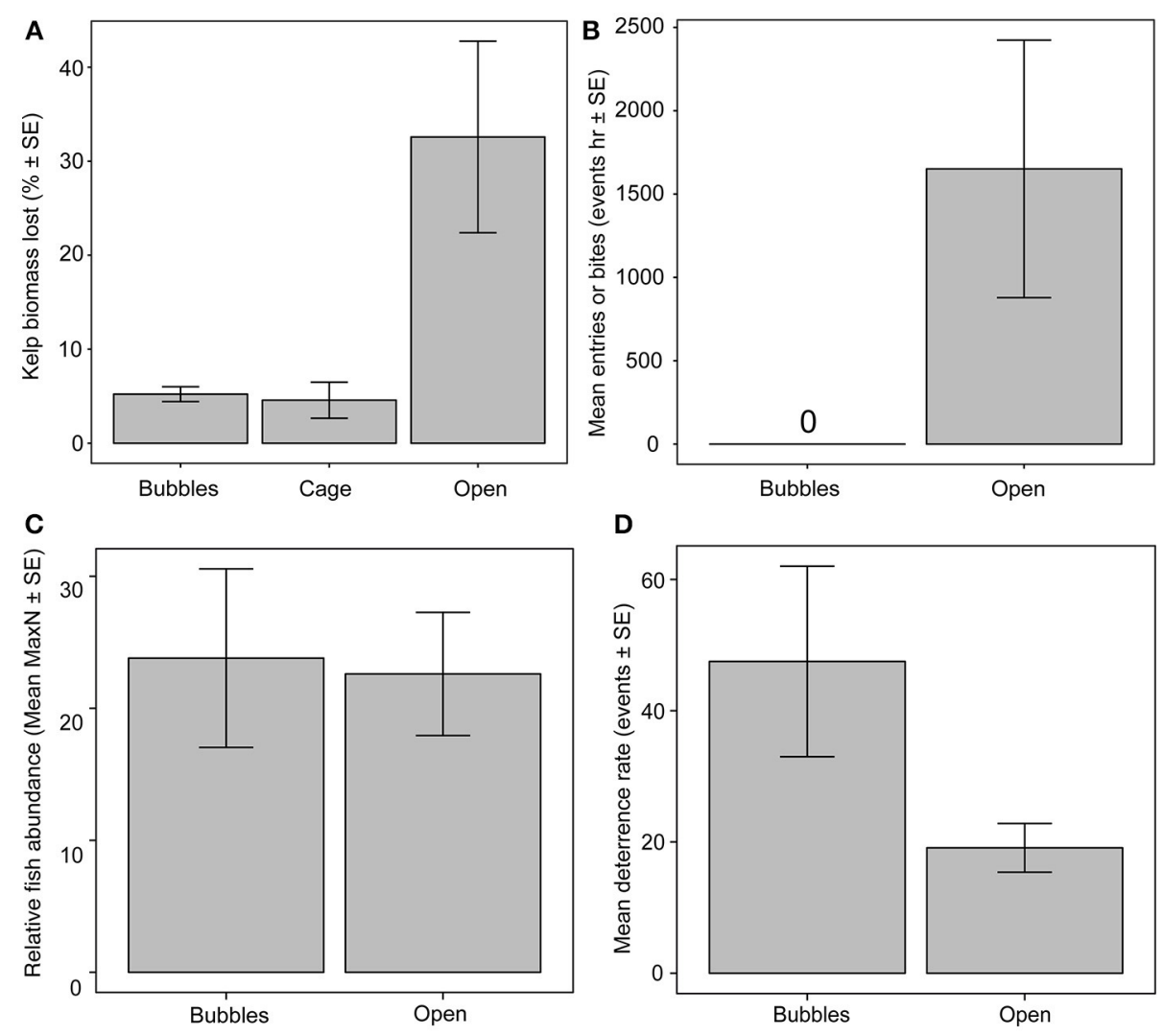

FIGURE 2 | Comparison of herbivore activity around bubble curtains, exclusion cages and unprotected plots for (A) kelp loss rates, (B) fish bite rates on kelp or entry rates through the bubble curtain, (C) relative abundance of herbivorous fishes (MaxN) outside of bubble curtain and unprotected kelp plots, (D) deterrence rates of herbivorous fishes (i.e., abrupt changes in swimming trajectory) away from bubble curtain or unprotected kelps.

unprotected kelps. Siganus fuscescens recorded 33,387 total bites followed by Kyphosus sydneyanus, K. bigibbus, and K. cornelli with a total of 2,235, 65, and 40 bites throughout the course of the experiment, respectively. In total, there were two occasions where a small, non-herbivorous fish (Coris auricularis and Epinephelus rivulatus) were observed to enter and exit through the base of the bubble curtain.

The absence of herbivore entries into the bubble curtain was not caused by fewer fish in the vicinity of the bubble curtains. Relative herbivore abundance did not differ between unprotected kelps and those surrounded by bubble curtains [ANOVA, $F_{(1,4)}$ $=0.049, p=0.0 .835$; Figure 2C]. Fishes approaching the bubble curtain altered their course, with $47.5 \pm 14.5$ deterrence events $\mathrm{h}^{-1}$ (mean $\pm \mathrm{SE}$ ), compared to $19.1 \pm 3.7$ deterrence events $\mathrm{h}^{-1}$ recorded around unprotected kelps, although this result was not significant [ANOVA, $F_{(1,4)}=4.417, p=0.103$; Figure 2D].

\section{DISCUSSION}

Overgrazing of marine vegetation by fish herbivores is an important ecological process in shallow subtidal ecosystems and can be a major impediment to the rehabilitation of foundation species such as kelps and seagrasses. Our experiments have revealed that bubble curtains can provide an effective alternative to rigid cages to exclude fish herbivores from vegetated areas in patches up to $3.14 \mathrm{~m}^{2}$. To our knowledge, our study is the first to assess the efficacy of bubble curtains to exclude marine herbivores and provides justification for future studies to examine their efficacy at larger, ecologically relevant scales that have previously been unfeasible with conventional rigid cages.

The potential of bubble curtains as herbivore exclusion devices is relevant given the rate of loss of coastal marine vegetation globally (Waycott et al., 2009; Krumhansl et al., 2016) and the profound influence herbivores can have on this process (Vergés et al., 2014). Indeed, Port Gregory where the current study took place, experienced $100 \%$ loss of kelp forests following a marine heatwave in 2011 that wiped out over $900 \mathrm{~km}^{2}$ of kelp forest in the region (Wernberg et al., 2016). Moreover, biomass and feeding rates by browsing herbivorous fishes in Port Gregory are among the highest to have been reported in the literature (Bennett et al., 2015), highlighting the relevance of these results for vegetated marine habitats elsewhere.

The effective exclusion of herbivorous fishes observed here is consistent with a general support for the use of bubble curtains, although the efficacy of bubble curtains for different underwater applications has been mixed. In aquarium experiments, bubbles have been shown to significantly reduce but not fully prevent the movements of invasive fishes including the Eurasian ruffe (Gymnocephalus cernuus) (Dawson et al., 2006) and common carp (Cyprinus carpio) irrespective of bubble size and density 
(Zielinski et al., 2014). Other freshwater fish species have shown mixed responses to bubble curtains in aquaria, ranging from moderate to low deterrence rates (Patrick et al., 1985; Sager et al., 1987). For fishes, several studies have reported that a combination of deterrence measures, such as bubbles with strobe lights provide the most effective deterrent (Patrick et al., 1985; Sager et al., 1987). More recent studies however, have suggested that it is the noise produced by the bubble curtains that acts as the primary deterrent, rather than the visual cue (Zielinski et al., 2014). In addition to producing sound, underwater bubbles can inhibit sound transmission through water due to density mismatch and concomitant reflection and absorption of sound waves (Würsig et al., 2000). In this sense they have been successfully applied to reduce underwater noise pollution from construction sites, benefiting marine mammals (Würsig et al., 2000; Lucke et al., 2011). In the current study, the high density of bubbles created an opaque curtain which was very visible in the relatively clear reef waters. Additionally, the opaque curtain made it difficult to see the transplanted kelp inside the enclosure. Therefore, while audio cues may have influenced fish behavior, it seems likely that the visual barrier produced by the bubbles would have also played an important role in modifying herbivore behavior.

While the findings of the current study are promising, several questions remain unanswered about how bubble curtains affect other physical and biological processes and the efficacy of bubble curtains over longer temporal and larger reef-scape scales. For example, the constant stream of bubbles may have localized upwelling effects that could influence processes such as larval and propagule settlement, sediment resuspension and sedimentation rates on benthic organisms, or erosion rates of seaweeds. Future studies should consider testing the effects of bubble curtains on physical and biological processes in addition to herbivory. Moreover, incorporating procedural controls, such partial bubble curtains, may help to discern some of the artifacts of bubble curtains and will be important design considerations when manipulating herbivores for long term or large scale studies.

With respect to scaling up the size of bubble curtains, some additional ecological and behavioral uncertainties include; (1) the potential for habituation of fishes to the bubbles over time, (2) the cumulative impact and management of sporadic breaches by fishes and (3) the influence of the bubble curtain on natural rates of recruitment of propagules and larvae. Studies of bubble curtains as shark deterrents found that after initial success, sharks eventually breached the curtain that was protecting a bag of burley (Hart and Collin, 2015). Sporadic pulses of large bubbles in conjunction with the continuous curtain of small bubbles are considered to be more effective at protecting the bait (Hart and Kempster personal communication). The impact of sporadic breaches into the exclusion area will depend largely on the size of the exclusion zone and the frequency of the breaches. Even if complete isolation from herbivores cannot be achieved, reducing herbivory rates by $\sim 80-90 \%$ may still be enough to revegetate the exclusion area. Future studies could consider including spontaneity and unpredictability in bubble supply to reduce the potential habituation and breaches by herbivores as well as testing the ability for larvae to pass through the bubble curtain and successfully settle in the exclusion area.

Other practical considerations related to scaling up bubble curtains include the capacity to provide even and continuous bubble supply and regular maintenance to ensure that gaps in the curtain do not form. The capacity to generate reliable air supply will be an important consideration for where, and how large, exclusion areas will be able to be installed. The relatively cheap installation of the system means that back-up systems could be installed at the same time by deploying multiple rows of air hose in case of localized interruptions to supply, or to generate different bubble types.

Underwater exclusion of fish herbivores, with minimal experimental artifacts is challenging, particularly at scales relevant to the home range of roving herbivorous fishes. On a fringing coral reef, for example, it has been estimated that the area required to exclude herbivores so that net algal production exceeds consumption would be $\sim 610 \mathrm{~kg}$ of standing Sargassum spp. biomass, equivalent to an area of 75-115 $\mathrm{m}^{2}$ (Hoey and Bellwood, 2011). This value is equivalent to the total area excluded by Hughes et al. (2007), on the same reef, in the largest herbivore exclusion experiment we are aware of. Following the removal of these exclusion cages, fishes readily consumed all Sargassum spp. within 2 months (Bellwood et al., 2006). As such $75-115 \mathrm{~m}^{2}$ is likely to be an underestimation of the area required for algal production to exceed consumption on many reefs where herbivore biomass is high-nevertheless it provides an interesting example of the mismatch in scaling between most exclusion studies (median exclusion area $0.06 \mathrm{~m}^{2}$ ) and the area required to re-establish self-sustaining areas of marine macrophytes.

Here we propose the use of bubble curtains as a potential alternative method to the use of rigid cages. We demonstrate that bubble curtains can effectively exclude fish herbivores herbivore for short term underwater experiments. This study provides support for future efforts to trial larger exclusion areas that may assist in the rehabilitation of benthic marine habitats that are susceptible to overgrazing. Moreover, bubble curtains may provide an opportunity to conduct exclusion experiments at a necessary scale to understand the dynamic role of herbivores on the resilience and stability of benthic marine ecosystems.

\section{AUTHOR CONTRIBUTIONS}

SB conceived the ideas; SB, TW, and TdB designed methodology and collected the data; SB analyzed the data; SB led the writing of the manuscript. All authors contributed critically to the drafts and gave final approval for publication.

\section{ACKNOWLEDGMENTS}

We thank Shaun Collin, Ryan Kempster and Nathan Hart for helpful discussion about methodology and practical issues. We thank Alistair Poore for providing data on the size and duration of exclusion studies. Also thanks to Maj-Britt Christensen for analysing the video footage and the constructive comments and 
suggestions by the reviewers. Research was funded by grants from the Hermon Slade Foundation (TW, SB) and the Australian Research Council (TW). SB received funding from the European Union's Horizon 2020 research and innovation programme under grant agreement No 659246.

\section{REFERENCES}

Arimoto, T., Akiyama, S., Kikuya, K., and Kobayashi, H. (1993). Fishherding effect of an air bubble curtain and its application to setnet fisheries. Fish Behav. Relat. Fish. Oper. 196, 155-160.

Bastyan, G., and Cambridge, M. (2008). Transplantation as a method for restoring the seagrass Posidonia australis. Estuar. Coast. Shelf Sci. 79, 289-299. doi: 10.1016/j.ecss.2008.04.012

Bellwood, D. R., and Choat, J. H. (1990). A functional analysis of grazing in parrotfishes (family Scaridae): the ecological implications. Environ. Biol. Fishes 28, 189-214. doi: 10.1007/978-94-009-2065-1_11

Bellwood, D. R., Hughes, T. P., and Hoey, A. S. (2006). Sleeping functional group drives coral-reef recovery. Curr. Biol. 16, 2434-2439. doi: 10.1016/j.cub.2006.10.030

Bellwood, D., Hughes, T., Folke, C., and Nyström, M. (2004). Confronting the coral reef crisis. Nature 429, 827-833. doi: 10.1038/nature02691

Bennett, S., Wernberg, T., Connell, S. D., Hobday, A. J., Johnson, C. R., and Poloczanska, E. S. (2016). The' Great Southern Reef': social, ecological and economic value of Australia's neglected kelp forests. Mar. Freshw. Res. 67, 47-56. doi: 10.1071/MF15232

Bennett, S., Wernberg, T., Harvey, E. S., Santana-Garcon, J., and Saunders, B. J. (2015). Tropical herbivores provide resilience to a climate-mediated phase shift on temperate reefs. Ecol. Lett. 18, 714-723. doi: 10.1111/ele. 12450

Bertness, M. D., Brisson, C. P., Coverdale, T. C., Bevil, M. C., Crotty, S. M., and Suglia, E. R. (2014). Experimental predator removal causes rapid salt marsh die-off. Ecol. Lett. 17, 830-835. doi: 10.1111/ele.12287

Burkepile, D. E., and Hay, M. E. (2008). Herbivore species richness and feeding complementarity affect community structure and function on a coral reef. Proc. Natl. Acad. Sci. U.S.A. 105, 16201-16206. doi: 10.1073/pnas.08019 46105

Campbell, A. H., Marzinelli, E. M., Vergés, A., Coleman, M. A., and Steinberg, P. D. (2014). Towards restoration of missing underwater forests. PLoS ONE 9:e84106. doi: 10.1371/journal.pone.0084106

Cappo, M., Harvey, E., Malcom, H., and Speare, P. (2003). "Potential of video techniques to monitor diversity, abundance and size of fish in studies of Marine Protected Areas," in World Congress on Aquatic Protected Areas Proceedings, eds J. P. Beumer, A. Grant, and D. C. Smith (Cairns, QLD: Society for Fish Biology), 455-464.

Dawson, H. A., Reinhardt, U. G., and Savino, J. F. (2006). Use of electric or bubble barriers to limit the movement of Eurasian ruffe (Gymnocephalus cernuus). J. Great Lakes Res. 32, 40-49. doi: 10.3394/0380-1330(2006)32[40:UOEOBB]2.0. $\mathrm{CO} ; 2$

Filbee-Dexter, K., and Scheibling, R. E. (2014). Sea urchin barrens as alternative stable states of collapsed kelp ecosystems. Mar. Ecol. Prog. Ser. 495, 1-25. doi: 10.3354/meps10573

Hart, N. S., and Collin, S. P. (2015). Sharks senses and shark repellents. Integr. Zool. 10, 38-64. doi: 10.1111/1749-4877.12095

Hoey, A. S., and Bellwood, D. R. (2011). Suppression of herbivory by macroalgal density: a critical feedback on coral reefs? Ecol. Lett. 14, 267-273. doi: 10.1111/j.1461-0248.2010.01581.x

Hughes, T. P., Rodrigues, M. J., Bellwood, D. R., Ceccarelli, D., Hoegh-Guldberg, O., McCook, L., et al. (2007). Phase shifts, herbivory, and the resilience of coral reefs to climate change. Curr. Biol. 17, 360-365. doi: 10.1016/j.cub.2006.12.049

Krumhansl, K. A., Okamoto, D. K., Rassweiler, A., Novak, M., Bolton, J. J., Cavanaugh, K. C., et al. (2016). Global patterns of kelp forest change over the past half-century. Proc. Natl. Acad. Sci. U.S.A. 113, 13785-13790. doi: $10.1073 /$ pnas. 1606102113

\section{SUPPLEMENTARY MATERIAL}

The Supplementary Material for this article can be found online at: http://journal.frontiersin.org/article/10.3389/fmars. 2017.00302/full\#supplementary-material

Ling, S., Johnson, C., Frusher, S., and Ridgway, K. (2009). Overfishing reduces resilience of kelp beds to climate-driven catastrophic phase shift. Proc. Natl. Acad. Sci. U.S.A. 106, 22341-22345. doi: 10.1073/pnas.0907529106

Linnansaari, T., Wallace, B., Curry, R., and Yamazaki, G. (2015). Fish Passage in Large Rivers: A Literature Review. Mactaquac Aquatic Ecosystem Study Report Series 2015-2016.

Lucke, K., Lepper, P. A., Blanchet, M. A., and Siebert, U. (2011). The use of an air bubble curtain to reduce the received sound levels for harbor porpoises (Phocoena phocoena). J. Acoust. Soc. Am. 130, 3406-3412. doi: $10.1121 / 1.3626123$

McClanahan, T. R., Kamukuru, A., Muthiga, N., Yebio, M. G., and Obura, D. (1996). Effect of sea urchin reductions on algae, coral, and fish populations. Conserv. Biol.10, 136-154. doi: 10.1046/j.1523-1739.1996.10010136.x

Menge, B. A., Daley, B. A., Lubchenco, J., Sanford, E., Dahlhoff, E., Halpin, P. M., et al. (1999). Top-down and bottom-up regulation of New Zealand rocky intertidal communities. Ecol. Monogr. 69, 297-330. doi: 10.1890/00129615(1999)069[0297:TDABUR]2.0.CO;2

Mumby, P. J., Dahlgren, C. P., Harborne, A. R., Kappel, C. V., Micheli, F., Brumbaugh, D. R., et al. (2006). Fishing, trophic cascades, and the process of grazing on coral reefs. Science 311, 98-101. doi: 10.1126/science.1121129

Neumann, D. R., and Orams, M. B. (2003). Feeding behaviours of short-beaked common dolphins, Delphinus delphis, in New Zealand. Aquat. Mammals 29, 137-149. doi: 10.1578/016754203101023997

Orth, R. J., Carruthers, T. J. B., Dennison, W. C., Duarte, C. M., Fourqurean, J. W., Heck, K. L., et al. (2006). A global crisis for seagrass ecosystems. Bioscience 56, 987-996. doi: 10.1641/0006-3568(2006)56[987:AGCFSE]2.0.CO;2

Pagès, J. F., Bartumeus, F., Hereu, B., López-Sanz, À., Romero, J., and Alcoverro, T. (2013). Evaluating a key herbivorous fish as a mobile link: a Brownian bridge approach. Mar. Ecol. Prog. Ser. 492, 199-210. doi: 10.3354/meps10494

Pagès, J. F., Farina, S., Gera, A., Arthur, R., Romero, J., and Alcoverro, T. (2012). Indirect interactions in seagrasses: fish herbivores increase predation risk to sea urchins by modifying plant traits. Funct. Ecol. 26, 1015-1023. doi: 10.1111/j.1365-2435.2012.02038.x

Patrick, P. H., Christie, A., Sager, D., Hocutt, C., and Stauffer, J. (1985). Responses of fish to a strobe light/air-bubble barrier. Fish Res. 3, 157-172. doi: 10.1016/0165-7836(85)90016-5

Poore, A. G., Campbell, A. H., Coleman, R. A., Edgar, G. J., Jormalainen, V., Reynolds, P. L., et al. (2012). Global patterns in the impact of marine herbivores on benthic primary producers. Ecol. Lett. 15, 912-922. doi: 10.1111/j.1461-0248.2012.01804.x

Sager, D. R., Hocutt, C. H., and Stauffer, J. R. (1987). Estuarine fish responses to strobe light, bubble curtains and strobe light/bubble-curtain combinations as influenced by water flow rate and flash frequencies. Fish Res. 5, 383-399. doi: 10.1016/0165-7836(87)90054-3

Sharpe, F., and Dill, L. (1997). The behavior of Pacific herring schools in response to artificial humpback whale bubbles. Can. J. Zool. 75, 725-730. doi: $10.1139 / \mathrm{z} 97-093$

Statton, J., Cambridge, M. L., Dixon, K. W., and Kendrick, G. A. (2013). Aquaculture of Posidonia australis seedlings for seagrass restoration programs: effect of sediment type and organic enrichment on growth. Restor. Ecol. 21, 250-259. doi: 10.1111/j.1526-100X.2012.00873.x

Statton, J., Gustin-Craig, S., Dixon, K. W., and Kendrick, G. A. (2015). Edge effects along a seagrass margin result in an increased grazing risk on Posidonia australis transplants. PLoS ONE 10:e0137778. doi: 10.1371/journal.pone.0137778

Stewart, P. A. (1982). An investigation into the reactions of fish to electrified barriers and bubble curtains. Fish Res. 1, 3-22. doi: 10.1016/0165-7836(81)90003-5 
Sumi, C. B., and Scheibling, R. E. (2005). Role of grazing by sea urchins Strongylocentrotus droebachiensis in regulating the invasive alga Codium fragile ssp. tomentosoides in Nova Scotia. Mar. Ecol. Prog. Ser. 292, 203-212. doi: 10.3354/meps292203

Vergés, A., Doropoulos, C., Malcolm, H. A., Skye, M., Garcia-Piz,á, M., Marzinelli, E. M., et al. (2016). Long-term empirical evidence of ocean warming leading to tropicalization of fish communities, increased herbivory, and loss of kelp. Proc. Natl. Acad. Sci. U.S.A. 113, 13791-13796. doi: 10.1073/pnas.1610725113

Vergés, A., Steinberg, P. D., Hay, M. E., Poore, A. G., Campbell, A. H., Ballesteros, E., et al. (2014). The tropicalization of temperate marine ecosystems: climatemediated changes in herbivory and community phase shifts. Proc. R. Soc. B Biol. Sci. 281:20140846. doi: 10.1098/rspb.2014.0846

Waycott, M., Duarte, C. M., Carruthers, T. J. B., Orth, R. J., Dennison, W. C., Olyarnik, S., et al. (2009). Accelerating loss of seagrasses across the globe threatens coastal ecosystems. Proc. Natl. Acad. Sci. U.S.A. 106, 12377-12381. doi: 10.1073/pnas.0905620106

Welsh, J., and Bellwood, D. (2014). Herbivorous fishes, ecosystem function and mobile links on coral reefs. Coral Reefs 33, 303-311. doi: 10.1007/s00338-014-1124-7

Wernberg, T., Bennett, S., Babcock, R. C., de Bettignies, T., Cure, K., Depczynski, M., et al. (2016). Climate-driven regime shift of a temperate marine ecosystem. Science 353, 169-172. doi: 10.1126/science.aad8745

Wernberg, T., Smale, D. A., Tuya, F., Thomsen, M. S., Langlois, T. J., de Bettignies, T., et al. (2013). An extreme climatic event alters marine ecosystem structure in a global biodiversity hotspot. Nat. Clim. Chang. 3, 78-82. doi: $10.1038 /$ nclimate 1627

Wiley, D., Ware, C., Bocconcelli, A., Cholewiak, D., Friedlaender, A., Thompson, M., et al. (2011). Underwater components of humpback whale bubble-net feeding behaviour. Behaviour 148, 575-602. doi: 10.1163/000579511X570893
Wismer, S., Hoey, A., and Bellwood, D. R. (2009). Cross-shelf benthic community structure on the Great Barrier Reef: relationships between macroalgal cover and herbivore biomass. Mar. Ecol. Prog. Ser. 376, 45-54. doi: 10.3354/meps 07790

Wolf, E. C., Cooper, D. J., and Hobbs, N. T. (2007). Hydrologic regime and herbivory stabilize an alternative state in Yellowstone National Park. Ecol. Appl. 17, 1572-1587. doi: 10.1890/06-2042.1

Würsig, B., Greene, C., and Jefferson, T. (2000). Development of an air bubble curtain to reduce underwater noise of percussive piling. Mar. Environ. Res. 49, 79-93. doi: 10.1016/S0141-1136(99)00050-1

Zielinski, D., Voller, V., Svendsen, J., Hondzo, M., Mensinger, A., and Sorensen, P. (2014). Laboratory experiments demonstrate that bubble curtains can effectively inhibit movement of common carp. Ecol. Eng. 67, 95-103. doi: 10.1016/j.ecoleng.2014.03.003

Conflict of Interest Statement: The authors declare that the research was conducted in the absence of any commercial or financial relationships that could be construed as a potential conflict of interest.

The reviewer RS and handling Editor declared their shared affiliation, and the handling Editor states that the process nevertheless met the standards of a fair and objective review.

Copyright (C) 2017 Bennett, Wernberg and de Bettignies. This is an open-access article distributed under the terms of the Creative Commons Attribution License (CC BY). The use, distribution or reproduction in other forums is permitted, provided the original author(s) or licensor are credited and that the original publication in this journal is cited, in accordance with accepted academic practice. No use, distribution or reproduction is permitted which does not comply with these terms. 